\title{
Combining Bioenergy with CCS
}

Reporting and Accounting

for Negative Emissions under UNFCCC and the Kyoto Protocol 



\section{Combining}

\section{Bioenergy with CCS}

\section{Reporting and Accounting \\ for Negative Emissions \\ under UNFCCC and \\ the Kyoto Protocol}

International Energy Agency 
The International Energy Agency (IEA), an autonomous agency, was established in November 1974. Its primary mandate was - and is - two-fold: to promote energy security amongst its member countries through collective response to physical disruptions in oil supply, and provide authoritative research and analysis on ways to ensure reliable, affordable and clean energy for its 28 member countries and beyond. The IEA carries out a comprehensive programme of energy co-operation among its member countries, each of which is obliged to hold oil stocks equivalent to 90 days of its net imports. The Agency's aims include the following objectives:

- Secure member countries' access to reliable and ample supplies of all forms of energy; in particular, through maintaining effective emergency response capabilities in case of oil supply disruptions.

- Promote sustainable energy policies that spur economic growth and environmental protection in a global context - particularly in terms of reducing greenhouse-gas emissions that contribute to climate change.

- Improve transparency of international markets through collection and analysis of energy data.

- Support global collaboration on energy technology to secure future energy supplies and mitigate their environmental impact, including through improved energy

efficiency and development and deployment of low-carbon technologies.

Find solutions to global energy challenges through engagement and dialogue with non-member countries, industry, international organisations and other stakeholders.

IEA member countries:

\section{Austria}

Belgium

Canada

Czech Republic

\section{Denmark}

Finland

France

Germany

Greece

Hungary

Ireland

Italy

Japan

Korea (Republic of)

Luxembourg

Netherlands

New Zealand

Norway

Poland

Portugal

(c) OECD/IEA, 2011

\section{International Energy Agency}

9 rue de la Fédération

75739 Paris Cedex 15, France

www.iea.org

Please note that this publication

is subject to specific restrictions

that limit its use and distribution.

The terms and conditions are available

online at www.iea.org/about/copyright.asp

Slovak Republic

Spain

Sweden

Switzerland

Turkey

United Kingdom

United States

The European Commission

also participates in

the work of the IEA. 


\section{Table of Contents}

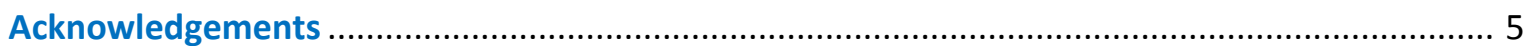

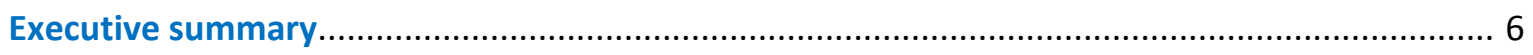

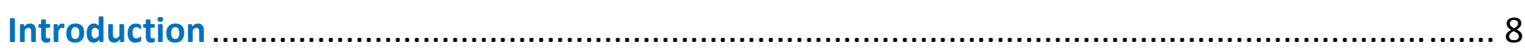

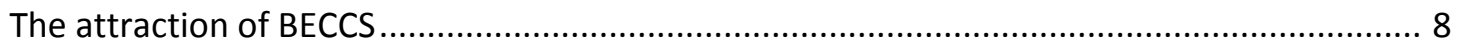

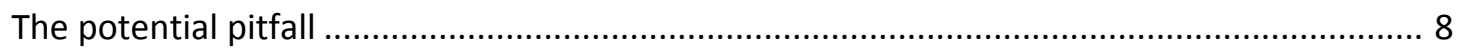

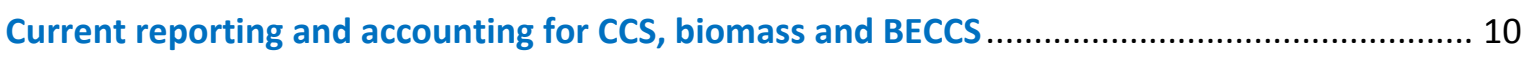

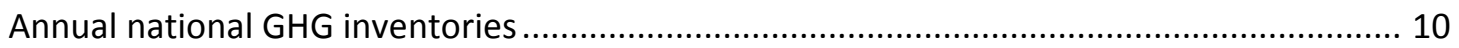

Current reporting guidance for biomass under the UNFCCC ….............................................. 12

Arrangements for reporting LULUCF information under the Kyoto Protocol .......................... 13

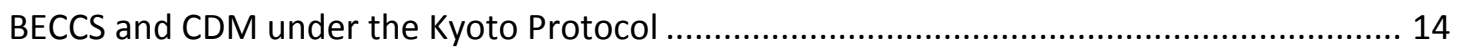

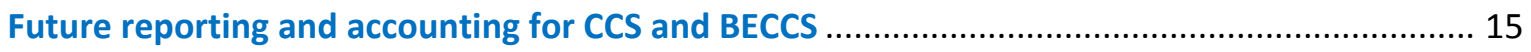

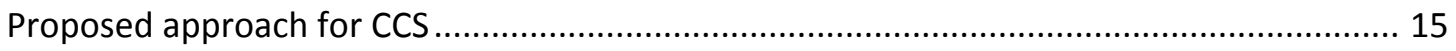

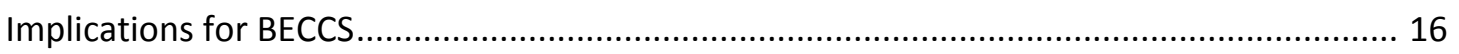

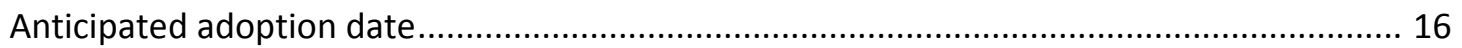

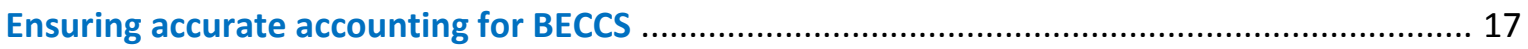

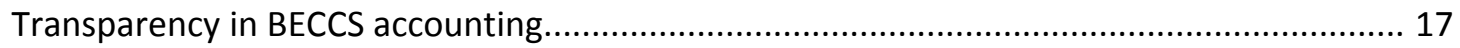

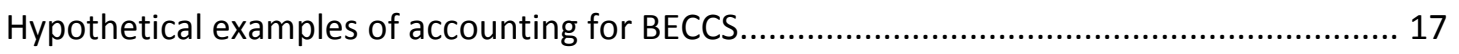

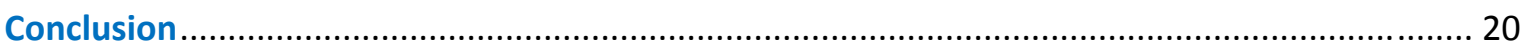

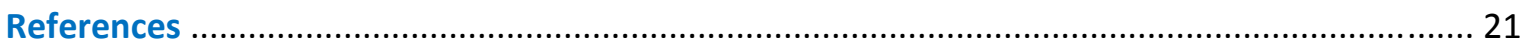

Annex 1: Preparation of annual GHG inventories under the UNFCCC and Kyoto Protocol ........... 22

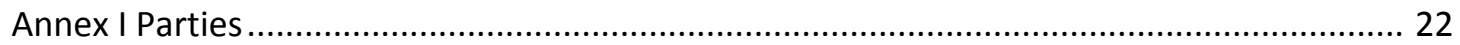

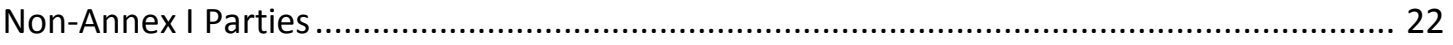

Annex 2: Hypothetical example of reporting national emissions and removals

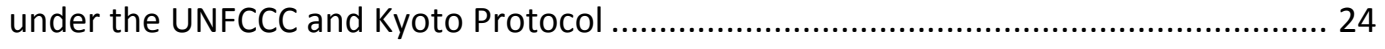

Annex 3: Example of reporting BECCS in annual national GHG inventory .................................... 26

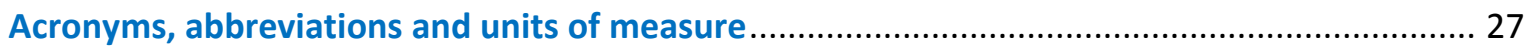

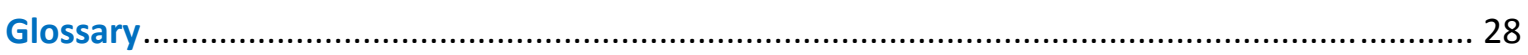

\section{List of boxes}

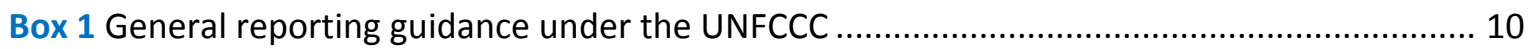

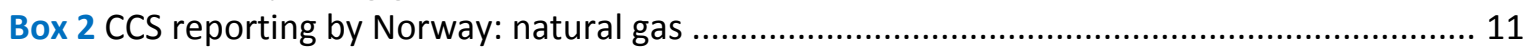

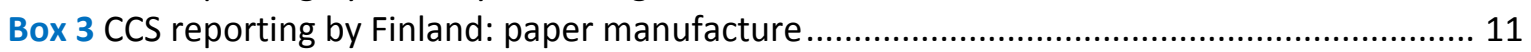

Box 4 Supplementary reporting requirements on the LULUCF sector under the Kyoto Protocol.. 13

Box 5 Equation used in reporting reduced emissions from CCS................................................. 16 
List of figures

Figure 1 Reporting emissions of $\mathrm{CO}_{2}$ from biomass in national GHG inventory

List of tables

Page | 4

Table 1 Hypothetical example of reporting national emissions and removals.

Table 2 Reporting of $\mathrm{CO}_{2}$ emissions and removals in the GHG inventory of a CHP plant in the pulp and paper industry 


\section{Acknowledgements}

This paper is based on a draft written by Riitta Pipatti, Statistics Finland. Thanks is due to Dr Simon Eggleston, IPCC Task Force on National Greenhouse Gas Inventories, to Paul Zakkour, Carbon Counts, for providing reviews, and to our editor, Justin French-Brooks, for helping to express a difficult subject in plain language. 


\section{Executive summary}

Bioenergy with Carbon Capture and Storage (BECCS) is a carbon reduction technology offering permanent net removal of carbon dioxide $\left(\mathrm{CO}_{2}\right)$ from the atmosphere. This has been termed "negative carbon emissions", and offers a significant advantage over other mitigation

Page I 6 alternatives, which only decrease the amount of emissions to the atmosphere. BECCS is able to do this because it uses biomass that has removed atmospheric carbon while it was growing, and then stores the carbon emissions resulting from combustion permanently underground.

It has been suggested that BECCS could be applied to a wide range of biomass-related technologies, and may also be attractive from a relative cost perspective. To date, however, the combination of bioenergy and carbon capture and storage (CCS) has not been fully recognised or realised. Incentive policies to support BECCS need to be based on an assessment of the net impact on emissions that the technology can achieve. This paper reviews how "negative emissions" are dealt with under international greenhouse gas (GHG) accounting frameworks, and highlights the need for internationally compatible accounting policy that incorporates all emissions generated by BECCS over its lifecycle.

\section{The need for compatible accounting rules}

In order for negative emissions from BECCS to be fully acknowledged, carbon accounting mechanisms need to be in place that allow their benefits to be realised by those countries investing in it. International climate reporting guidelines, as they currently apply to industrialised countries (known as Annex I Parties), only make passing reference to CCS, and accounting guidelines relating to Kyoto Protocol commitments make no mention of it at all. Furthermore, a key method of meeting Kyoto Protocol commitments, the Clean Development Mechanism (CDM), does not currently allow for CCS projects.

Revised carbon reporting guidelines were developed by the Intergovernmental Panel on Climate Change (IPCC) in 2006. These make specific reference to CCS and provide methodological guidance to ensure that it is reported accurately and fairly in national GHG inventories. They make no distinction between CCS using fossil or biomass fuel sources, and therefore the environmentally sound system it stipulates applies to both. Importantly they also make clear how negative emissions would be accounted for.

The revised IPCC guidelines have not been adopted in respect of Annex I Parties, but they are envisaged to become binding for GHG reporting from 2015. Two Annex I Parties, Norway and Finland, have already followed the guidelines and registered the carbon benefits. This is likely to bring a greater degree of certainty to those considering investing in BECCS.

\section{Biomass sustainability: the next obstacle?}

Unlike conventional CCS, BECCS uses renewable biomass as a fuel. However, biomass can be produced unsustainably and may contribute to environmental degradation in a number of different ways - not just in the form carbon emissions from land-use changes, but also (for example) from water depletion and loss of biodiversity. Its damaging effects may outweigh the benefits of negative $\mathrm{CO}_{2}$ emissions offered by the technology.

The reporting of biomass-related emissions forms part of requirements under UNFCCC GHG reporting guidelines. Annex I Parties are required to report such emissions under what is known as the LULUCF sector (standing for land use, land-use change and forestry). However, while 
reporting may be comprehensive, the accounting for biomass impacts under the Kyoto Protocol may not be, as Parties are able to opt into or out of accounting for certain LULUCF activities. This raises the possibility of the GHG benefits of BECCS counting towards Kyoto Protocol GHG commitments, but the disbenefits of using unsustainable biomass in BECCS being ignored.

A further risk arises from the prospect of an Annex I Party establishing a BECCS project that is fuelled by biomass from a developing country (known as a non-Annex I Party). Any assessment of biomass sustainability could realistically not be made from GHG reporting, as non-Annex I Parties are not required to report annually or in great detail. This could lead to a situation where the Annex I Party benefits from negative emissions against its Kyoto Protocol commitments, but even greater positive emissions go unreported in the country where the biomass was sourced.

It is therefore suggested that the question of biomass sustainability in the context of the Kyoto Protocol should be addressed as soon as possible, so as not to hold back the adoption of BECCS or allow its reputation to be damaged. 


\section{Introduction}

The IPCC has concluded that significant reductions in worldwide GHG emissions are needed to limit the increase in global temperatures to between $2^{\circ} \mathrm{C}$ and $4^{\circ} \mathrm{C}$. The International Energy Agency (IEA) has identified the widespread deployment of CCS as a key climate mitigation option.

Page $\mid 8$ It estimates that CCS will need to contribute about one-fifth of total reductions in emissions by 2050, in a least-cost strategy of stabilising atmospheric $\mathrm{CO}_{2}$ concentrations below 450 parts per million (ppm) (IEA, 2010).

Using biomass as an alternative to fossil fuels, and subjecting the resulting $\mathrm{CO}_{2}$ emissions to $\mathrm{CCS}$, has the potential to deliver "negative emissions" through the long-term removal of carbon from the biogenic cycle. The geological storage of $\mathrm{CO}_{2}$ from biomass can create a net reduction of atmospheric $\mathrm{CO}_{2}$, because under this scenario carbon has been absorbed by the biomass during its growth, but the carbon is not released into the atmosphere when it is combusted.

The process of using biomass as a fuel and then transporting and storing the resultant $\mathrm{CO}_{2}$ securely underground is known as BECCS, an acronym first used by Fisher et al. (2007).

\section{The attraction of BECCS}

Interest in BECCS has grown rapidly as it has the potential to offer deep reductions in atmospheric $\mathrm{CO}_{2}$ concentrations. It also appears to be practicable and cost-effective. The IPCC Special Report on Renewable Energy Sources and Climate Change Mitigation addresses this in some detail (2011). It states that successful deployment of CCS in combination with biomass conversion could result in removals of greenhouse gases from the atmosphere at attractive mitigation cost levels. BECCS offers the potential to achieve long-term reductions in GHG emissions necessary to stabilise atmospheric $\mathrm{CO}_{2}$ concentrations, and could be applied to a wide range of biomass-related technologies (Global CCS Institute, 2010).

While conventional CCS is well known as a carbon reduction technique and is discussed as a critical technology in fighting climate change, BECCS appears to have a much lower profile despite its potential to reverse historic GHG emissions, not merely reduce current emissions.

\section{The potential pitfall}

There is a potential pitfall that could undermine the positive opportunities provided by BECCS. The biomass used during conversion into energy may or may not come from sustainable sources. The use of unsustainable biomass in BECCS could negate any carbon benefits, and may even cause net positive $\mathrm{CO}_{2}$ emissions rather than reductions.

The IPCC has also noted that both direct land-use changes (such as conversion and forest management that lead to a loss of carbon stocks) and indirect land-use changes can lessen, and possibly more than neutralise, any of the net positive GHG mitigation impacts deriving from BECCS.

Activity boundaries are therefore critical when assessing the pros and cons of BECCS projects. Inclusion of the impacts on land use and land-use changes may change the amount of total avoided emissions significantly, and are likely to depend heavily on the specific cases and circumstances. To assume that BECCS is beneficial in all cases would be simplistic. 
For this reason it immediately becomes clear that the way in which BECCS projects are reported and accounted for under the UNFCCC and Kyoto Protocol is critical. Transparent reporting and accounting would ensure that all emissions and removals associated with a BECCS project are recognised, irrespective of its location or the place of origin of its fuel.

This paper explores current and forthcoming GHG reporting guidelines as they relate to BECCS, and their relationship with biomass sustainability.

For the purposes of this paper the definitions of "reporting" and "accounting" follow the IPCC definitions:

- Reporting means the process of providing calculated estimates of GHG emissions and removals to the UNFCCC. This is carried out by both Annex I and non-Annex I Parties.

- Accounting refers to the rules for comparing the emissions and removals as reported with commitments under the Kyoto Protocol. As only Annex I Parties have carbon reduction commitments, the accounting rules only apply to them. 


\section{Current reporting and accounting for CCS, biomass and BECCS}

The potential to reduce atmospheric $\mathrm{CO}_{2}$ levels offered by BECCS is unlikely to be realised unless

Page | 10 there is an incentive to deploy it. An appropriate incentive policy for BECCS needs to be based on an assessment of the emissions reduction that the technology can deliver. This section explains the current arrangements for reporting emissions under the UNFCCC, with a particular focus on biomass.

As background information, Box 1 provides detail on the reporting and accounting requirements for Parties to the UNFCCC.

Box 1 General reporting guidance under the UNFCCC

Reporting of anthropogenic GHG emissions and removals is mandatory for all Parties to the UNFCCC. The reporting requirements are different for industrialised (Annex I Parties) and developing country (non-Annex I Parties) parties with respect to timing and detail. Reporting requirements are significantly more onerous for Annex I Parties.

Common to all Parties is that the rules for reporting are agreed by the Conference of the Parties to the UNFCCC, and that the methodological guidance is based on the IPCC guidelines for national GHG inventories. The UNFCCC does not include any binding requirements for limiting or reducing national emissions.

\section{Annex I Party Commitments}

The Kyoto Protocol to the UNFCCC includes commitments for Annex I Parties to limit or reduce their emissions during the first commitment period 2008-12. The overall commitment for Annex I Parties jointly is to reduce their anthropogenic emissions by at least $5 \%$ during the commitment period compared to emissions in 1990. Quantified emission limitation and reduction commitments by Parties are specified in Annex B of the Kyoto Protocol and range from $-8 \%$ to $+10 \%$. Annex B includes GHG emissions from energy, industrial processes, solvent and product use, agriculture and waste. The emissions from the LULUCF sector are included only partially in the commitments, and depend also on choices made by Parties.

\section{National Greenhouse Gas Inventories}

Overall compliance by Annex I Parties with Kyoto Protocol commitments is assessed using national GHG inventories, prepared in accordance with the accounting rules specified in the Protocol and subsequent decisions by the Conference of Parties to the Protocol. The accounting rules allow commitments to be met using units acquired from emissions trading, Joint Implementation (JI) projects with other Annex I Parties, and from emission reduction projects in developing countries (CDM projects).

\section{Non-Annex I Parties}

Developing countries have no emission limitation or reduction commitments under the Kyoto Protocol.

\section{Annual national GHG inventories}

As highlighted in Box 1 above, all Parties to the UNFCCC are required to report on their anthropogenic GHG emissions and removals. Full details on the arrangements for preparation of annual GHG inventories under the UNFCCC and Kyoto Protocol are presented in Annex 1 to this document. 
Annex I Parties must submit their annual inventories to the UNFCCC by 15 April each year, and reporting is required for six sectors:

- energy;

- industrial processes;

- $\quad$ solvent and product use;

- agriculture;

- land use, land-use change and forestry (LULUCF); and

- waste.

It is important to note that total national emissions are reported in two ways: with and without the emissions from the LULUCF sector.

The UNFCCC reporting guidelines do not currently give specific guidance on how to treat CCS or negative emissions from BECCS. They address CCS only in one place, stating that the national inventory report should include "information on how the effects of $\mathrm{CO}_{2}$ capture from flue gases and subsequent $\mathrm{CO}_{2}$ storage are accounted for in the inventory." Under the Kyoto Protocol there are no formal rules that specifically address CCS.

However, emission reductions from CCS have been accepted in inventory reviews for Annex I Parties, and the reductions have been taken into account in assessing compliance with commitments. This is the case for both Norway and Finland, as described in Boxes 2 and 3 below.

Box 2 CCS reporting by Norway: natural gas

Norway reports on CCS in relation to the removal of $\mathrm{CO}_{2}$ from natural gas. Natural gas is extracted from the seabed and, as the $\mathrm{CO}_{2}$ content in the gas is higher than required, it is lowered through capture to ensure the correct quality for delivery to customers. The captured $\mathrm{CO}_{2}$ is injected into and stored in an aquifer below the seabed. Were the $\mathrm{CO}_{2}$ not re-injected under the seabed, it would be vented to the atmosphere.

The results of the CCS process are seen in the inventory as lower emissions from venting in oil and gas production. The emissions from the capture process and injection are reported separately. No emissions from the storage have been detected. The approach Norway has taken to reporting largely follows 2006 IPCC Guidelines, and has been accepted in reviews.

Box 3 CCS reporting by Finland: paper manufacture

A further example is the reporting in the Finnish inventory of capture of $\mathrm{CO}_{2}$ produced from combustion processes during the manufacture of paper. The $\mathrm{CO}_{2}$ is used in the production of precipitated calcium carbonate, which is itself used in paper production. Part of the $\mathrm{CO}_{2}$ comes from biogenic sources. The expert review teams have not questioned the reporting, although they have recommended that Finland subtract the part of captured and stored $\mathrm{CO}_{2}$ that comes from biomass. Finland has not agreed to this, at it believes that the approach in the 2006 IPCC Guidelines is the correct one.

As the expert review teams have not raised Finland's position as a problem, the captured and stored $\mathrm{CO}_{2}$ from biomass has been deducted from the total emissions in Finland's inventory for the first year of the current commitment period of the Kyoto Protocol. 


\section{Current reporting guidance for biomass under the UNFCCC}

Under current guidance used for preparing national GHG inventories, $\mathrm{CO}_{2}$ emissions from biomass are reported in the LULUCF sector as carbon stock changes in five pools and in six landuse categories.

Page | 12 The pools are:

- above-ground biomass;

- below-ground biomass;

- dead wood;

- litter; and

- soil organic carbon.

And the six land-use categories are:

- forest land;

- cropland;

- grassland;

- wetlands;

- $\quad$ settlements; and

- other land.

Emissions and removals associated with biomass are reported mainly in the LULUCF sector. The growth of woody biomass is reported as increase in carbon stock (removal of $\mathrm{CO}_{2}$ from the atmosphere), and when the biomass is harvested the default assumption is that the carbon is released to the atmosphere at the time of harvesting. ${ }^{1}$ For short-rotation plants like cereals, sugarcane and vegetables the carbon stock changes due to growth and harvesting are not included in the national inventories, as these are assumed to compensate each other over a short period.

While $\mathrm{CO}_{2}$ emissions from the combustion of biomass for energy ${ }^{2}$ are reported for reference purposes in the energy sector, the relevant $\mathrm{CO}_{2}$ emissions are not incorporated into the total emissions for the energy sector because they have already been reported in the LULUCF sector. Similarly, they are not incorporated into the total national emissions, which currently exclude the LULUCF sector when accounting under the Kyoto Protocol. Any long-term decline in the total carbon in standing biomass (e.g. forests) should be evident in the calculation of $\mathrm{CO}_{2}$ emissions in the LULUCF sector where the biomass is not used in a sustainable way.

In the energy sector $\mathrm{CO}_{2}$ emissions from biomass combustion are reported for reference purposes (information item). The methane and nitrous oxide emissions from biomass burning on the other hand are reported and included in the total emissions of the energy sector.

The reporting of the emissions associated with biomass in the national GHG inventory is illustrated in Figure 1.

\footnotetext{
${ }^{1}$ Carbon in harvest wood products (HWP) is not released to the atmosphere at the time of harvest. The delay in the emissions can be taken into account using different approaches. However, these are not presented here.

${ }^{2}$ This approach is also valid for the other sectors.
} 
Figure 1 Reporting emissions of $\mathrm{CO}_{2}$ from biomass in national GHG inventory

Growth

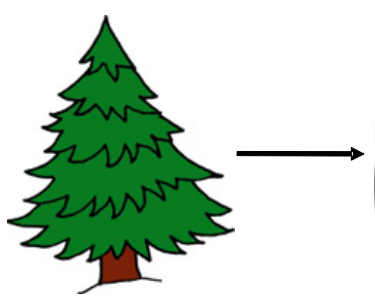

Gains in $\mathrm{C}$ stock are reported as $\mathrm{CO}_{2}$ removals in the LULUCF sector
Harvesting

Combustion
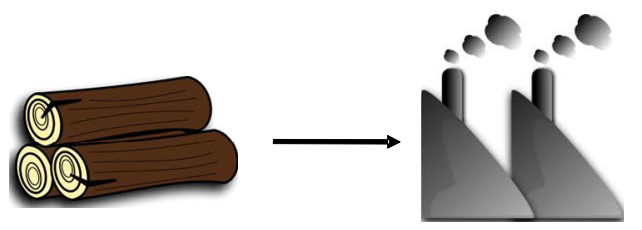
Losses in $\mathrm{C}$ stock are reported as $\mathrm{CO}_{2}$ emissions in the LULUCF sector

Figure 1 illustrates reporting of emissions from biomass growth, harvesting and combustion in national GHG inventories. Only the reporting of above-ground biomass is addressed in the figure. Loss of carbon due to harvesting is reported in the LULUCF sector, whereas when biomass is burned $\mathrm{CO}_{2}$ emissions are not reported or included in the emissions of the energy sector.

\section{Arrangements for reporting LULUCF information under the Kyoto Protocol}

Parties that have ratified the Kyoto Protocol are required to submit supplementary information in addition to the national GHG inventory described above. This must be in accordance with guidelines for preparation of information required under Article 7, paragraph 1 of the Kyoto Protocol (UNFCCC 2005). It includes, among other things, reporting on emissions from LULUCF activities in accordance with Article 3, paragraphs 3 and 4 of the Kyoto Protocol.

Under the Kyoto Protocol, the emission limitation and reduction commitments are based on the national total emissions without the LULUCF sector. Emissions and removals from land use and land-use change activities are taken into account only partly, as described in Box 4 below.

Box 4 Supplementary reporting requirements on the LULUCF sector under the Kyoto Protocol

The net emissions/removals of $\mathrm{CO}_{2}$ from afforestation/reforestation and deforestation (ARD) in accordance with Article 3, paragraph 3 of the Kyoto Protocol are reported and accounted as carbon stock changes and GHG emissions during the commitment period years on lands afforested/reforested and deforested since 1990. This reporting and accounting is mandatory for all Annex I Parties that have ratified the Kyoto Protocol and affects compliance with the commitments described in Annex B of the Protocol.

In addition, if a Party has elected forest management (FM), cropland management (CM), grazing land management (GM) and/or revegetation (RV) in accordance with Article 3, paragraph 4, the net emissions/removals from the elected activity in question are included in the reporting, and affect compliance with the commitments based on the following accounting rules:

For FM, accounting is based on the carbon stock changes and GHG emissions during the commitment period years (gross-net accounting). Also, for FM the accounting of the net emissions/removals is capped, i.e. only a part is taken into account.

For CM, GM and RV, accounting is based on the changes in the net emissions/removals in the commitment period compared to the base year (net-net accounting). 
A detailed hypothetical example of reporting national emissions and removals under the Kyoto Protocol is presented in Annex 2 to this document.

\section{BECCS and CDM under the Kyoto Protocol}

Page I 14 CCS under the CDM has been on the agenda of the international climate negotiations for some years. At the sixth Meeting of the Conference of Parties to the Kyoto Protocol (CMP) in Cancun in 2010, a decision was taken that CCS in geological formations should be eligible for project activities under the CDM. The decision is, however, provisional and requires that the following issues are addressed and resolved in a satisfactory manner:

- non-permanence, including long-term permanence;

- measuring, reporting and verification;

- environmental impacts;

- project activity boundaries;

- international law;

- liability;

- the potential for perverse outcomes;

- safety; and

- insurance coverage and compensation for damages caused due to seepage or leakage.

Capture and storage of $\mathrm{CO}_{2}$ from biomass have not been addressed specifically in the decision under CMP. 


\section{Future reporting and accounting for CCS and BECCS}

The IPCC has developed new guidelines for reporting GHG emissions, which specifically incorporate methodological guidance for CCS (IPCC, 2006). The 2006 IPCC guidelines follow the same approaches as the previous guidelines. The latest scientific knowledge has been incorporated to improve the accuracy of the inventories. Some reorganisation of sectors and categories, as well as inclusion of new greenhouse gases (e.g. $\mathrm{NF}^{3}$ ) and some new source and sink categories, have been made. The aim has been to increase scientific robustness and to improve consistency.

The methodological guidance for CCS is included in the volumes on "Energy" and "Industrial Processes and Product Use". The "General Guidance and Reporting" volume complements this guidance with general instructions on reporting of CCS.

\section{Proposed approach for CCS}

The main principle for taking CCS into account in inventories is that the captured $\mathrm{CO}_{2}$ should be deducted from the emissions produced only if the $\mathrm{CO}_{2}$ goes into long-term storage, and where emissions from transport and storage of the $\mathrm{CO}_{2}$ are monitored and reported using methods consistent with the IPCC guidelines for the these specific activities (as described in Volume 2, Chapter 5 of the 2006 guidance). ${ }^{3}$

For example, when captured $\mathrm{CO}_{2}$ is used in soft drinks, deduction of the captured $\mathrm{CO}_{2}$ is not allowed because this application is short term. Exceptions to this principle are made only when the captured $\mathrm{CO}_{2}$ emissions are reported elsewhere in the inventory. For example, captured $\mathrm{CO}_{2}$ from ammonia production that is then used in urea production can be deducted from the emissions of the ammonia plants, but only if the corresponding $\mathrm{CO}_{2}$ emissions are then reported in the agriculture sector where the urea is used as a fertiliser. ${ }^{4}$

In accordance with the 2006 IPCC Guidelines, CCS requires plant-specific reporting (at so-called Tier 3 level). The emission reductions due to capture need to be reported transparently based on measured data. The increase in energy consumption due to the capture processes will be reflected in the fuel statistics, and hence be taken into account in inventories by rule. These emissions will not be attributed to the CCS activity in the GHG inventory.

Emissions from leakage during transport, injection or storage of the capture $\mathrm{CO}_{2}$ are reported separately. The 2006 IPCC Guidelines provide methods and guidance for this.

As a quality assurance measure, the total $\mathrm{CO}_{2}$ mass balance of all national capture and storage projects needs to be provided in the national inventory report, also taking into account any imports and exports of $\mathrm{CO}_{2}$ to the storage facility/facilities in the country in question from other countries.

The equation used in reporting reduced emissions due the capture process is simple, as shown in Box 5 .

\footnotetext{
${ }^{3}$ The use of captured $\mathrm{CO}_{2}$ emissions in short-term applications can also reduce the overall GHG emissions if it replaces fossil $\mathrm{CO}_{2}$ produced specifically for the application. The substitution effect would be automatically taken into account in the inventory reporting. E.g. if captured $\mathrm{CO}_{2}$ replaced $\mathrm{CO}_{2}$ produced from combustion of natural gas, the reduction in the overall GHG emissions would be seen in the reduced emissions from the combustion of natural gas.

${ }^{4}$ Note that this would not apply in reporting under the UNFCCC at present as emissions from urea use in agriculture are reported as part of the emissions from ammonia production in the industrial process sector, not in the agriculture sector.
} 
Box 5 Equation used in reporting reduced emissions from CCS

- Emissions $_{\mathrm{s}}=$ Production $_{\mathrm{s}}-$ Capture $_{\mathrm{s}}$

Where:

- Capture $_{\mathbf{s}}=$ amount of $\mathrm{CO}_{2}$ captured

- Production ${ }_{\mathrm{s}}=$ estimated $\mathrm{CO}_{2}$ emissions, using the methods given in the 2006 IPCC guidelines assuming no capture

- Emissions $_{\mathbf{s}}=$ reported $\mathrm{CO}_{2}$ emissions for the source category

\section{Implications for BECCS}

In the 2006 IPCC Guidelines no distinction is made between $\mathrm{CO}_{2}$ from fossil or biomass sources in calculating and reporting CCS-related emissions in the energy or the industrial process sectors. If the plant where the capture takes places uses biomass, the $\mathrm{CO}_{2}$ emissions reported in the energy or industrial process sector will be zero, and the subtraction of the amount of $\mathrm{CO}_{2}$ captured and transferred to long-term storage will result in negative emissions. Any associated emissions from $\mathrm{CO}_{2}$ transport, $\mathrm{CO}_{2}$ injection and the storage reservoir will be accounted for in national total emissions, irrespective of whether the carbon originates from fossil sources or recent biomass production.

In theory, the reporting of negative emissions in the energy and industrial process sectors from BECCS ensures an environmentally sound system, when the corresponding emissions from the harvesting of the biomass are included under the LULUCF sector.

Similarly in the case of short-rotation biomass, where neither the uptake due to the plant growth nor emissions due to decay or burning are included in the inventory, the system is sound.

However, any assertions of soundness are based on an important assumption of comprehensive reporting in the LULUCF sector. Where reporting by Annex I Parties is incomplete as regards LULUCF, or where biomass has been sourced from non-Annex I Parties who are not required to report emissions in the LULUCF sector, the environmental integrity of the CCS-based process and the negative emissions will be open to question. This is investigated further in the next section.

\section{Anticipated adoption date}

These guidelines have yet to be adopted for reporting under the UNFCCC, but the UNFCCC has launched an adoption process. The aim is for Annex I countries to apply them for inventory reporting starting in 2015. This timing has been chosen so that reporting for the last year of the first commitment period of the Kyoto Protocol can be completed using existing IPCC guidelines and good practice. According to the Kyoto Protocol, new methodological guidance cannot be adopted for the first commitment period. 


\section{Ensuring accurate accounting for BECCS}

As described in the previous section, revised guidelines are likely to be adopted for reporting GHG emissions under the UNFCCC that specifically incorporate methodological guidance for CCS. These guidelines also appear to be compatible with BECCS, in that they present no barrier to reporting and accounting for negative emissions. However, there appear to be "missing links" under this scenario, resulting from potential gaps in Annex I Party accounting, and the contrasting reporting requirements placed on Annex I and non-Annex I Parties.

\section{Transparency in BECCS accounting}

Two important questions arise from current and proposed methodological guidance as they relate to BECCS. They are both in respect of the sustainability of the biomass used to generate heat and power.

First, while reporting on emissions and removals of GHG in the LULUCF sector is a requirement for Annex I Parties under their obligation to produce an annual national GHG inventory, the accounting for such changes under the Kyoto Protocol is only partial. Therefore, it may be possible under certain circumstances for an Annex I Party to use BECCS to comply with their Kyoto Protocol commitments, using biomass that has had detrimental impacts on their LULUCF sector, without any penalty. Where the Annex I Party has elected not to report on or account for $\mathrm{FM}, \mathrm{CM}, \mathrm{GM}$ and RV under LULUCF, any loss in carbon stocks in these categories may not be apparent.

Second, Annex I Parties may also opt to use BECCS and fuel the plant with biomass imported from a non-Annex I Party country. Under such a scenario the benefit of negative emissions would accrue to the Annex I Party, but the carbon impacts of the biomass sourced from overseas are likely to go unaccounted for. These impacts may arise not only from biomass cultivation, harvest, and processing, but also from detrimental changes to land use.

Two hypothetical examples are provided below to demonstrate how these questions may arise in practical situations.

\section{Hypothetical examples of accounting for BECCS}

\section{CHP in the pulp and paper industry}

The first hypothetical example is a CHP plant with a capacity of $180 \mathrm{MW}$ using bark and other wood-based residues and by-products as fuel. The amount of $\mathrm{CO}_{2}$ produced annually is around $0.2 \mathrm{Mt}^{5}{ }^{5} \mathrm{~A}$ capture unit installed close to the plant captures $90 \%$ of the $\mathrm{CO}_{2}$. The energy demand of the capture unit is estimated to be $30 \%$ of energy production output, is assumed to be produced using fossil fuels ${ }^{6}$, and results in annual emissions in the order of $0.05 \mathrm{Mt} \mathrm{CO}_{2}$ eq including the non- $\mathrm{CO}_{2}$ emissions.

\footnotetext{
${ }^{5}$ The non- $\mathrm{CO}_{2} \mathrm{GHG}$ emissions from the energy production at the pulp and paper plant are not considered. $\mathrm{Non}-\mathrm{CO}_{2}$ emissions would be approximately $1 \%-2 \%$ of the emissions of wood combustion using FBC, and less for the other technologies. The capture process would not affect these emissions if the $\mathrm{CO}_{2}$ were separated from the flue gases during the capture process.

${ }^{6}$ Pulp and paper processes produce heat in the form of steam, part of which cannot be utilised by the plant. There may be possibilities to use part of this in the capture process and thus decrease the amount of additional energy needed.
} 
The following assumptions are made:

- the $\mathrm{CO}_{2}$ is compressed and transported through pipelines to a geological site $100 \mathrm{~km}$ from the capture site;

- emissions from the compression and pipeline transport are $0.002 \mathrm{Mt} \mathrm{CO}_{2}(1 \%$ of the total emissions of the plant);

- injection to the storage site adds $0.001 \mathrm{Mt}$ to emissions;

- no emissions from the storage site take place;

- the storage site meets the requirements of long-term storage; and

- monitoring of potential leakage is done in accordance with the 2006 IPCC Guidelines.

In the GHG inventory the emissions from harvesting the biomass should have been reported under the LULUCF sector when the wood was harvested, in this case in the same year that combustion and capture took place. The $\mathrm{CO}_{2}$ emissions from the biomass combustion at the plant are reported for information in the energy sector but not included in the total national emissions. The increased emissions from capture are included in total emissions of the energy sector and included in the national total emissions.

In the reporting of the avoided emissions from the capture, the approach given in the 2006 IPCC Guidelines is used. The amount of captured $\mathrm{CO}_{2}, 0.018 \mathrm{Mt}$, would be reported as negative emissions in the Common Reporting Framework (CRF) category where the capture takes place. The reporting as described above is summarised in Table 2 in Annex 3, assuming that all activities (biomass production, the CHP and storage of the captured $\mathrm{CO}_{2}$ ) take place within the same Annex I Party.

This is the point where additional proof of sustainability would be warranted for the biomass used to generate negative emissions from CCS. The partial accounting of biomass growth and harvesting under the Kyoto Protocol could lead to potentially misleading outcomes, where zero emissions are claimed in the energy sector, and negative emissions from the further application of CCS, as in this case.

The mandatory accounting of deforestation under the Kyoto Protocol would cover emissions in cases where the biomass production has led to detrimental land-use changes in Annex I Parties. The accounting of forest management would also take into account the loss in carbon stock in the forest due to the harvesting of the biomass for the process, although it should be noted that this is voluntary. Additional proof of the sustainability of the biomass used could be obtained from national GHG inventories. A comparison of the total $\mathrm{CO}_{2}$ emissions from biomass combustion reported for information in the energy sector, as against the carbon stock changes in forest land reported in the LULUCF sector, should give an estimation of the sustainability of the wood use in the country.

However, where the biomass used by the plant was imported from a developing country (nonAnnex I Party) an assessment of the sustainability of the biomass could not be made from inventory information, as developing countries do not produce an inventory annually, and the quality of the inventories is not ensured through international reviews or other means. This could lead to a situation where an Annex I Party could report and account negative emissions using BECCS, even where the biomass it used caused significant emissions in the country where it was produced.

In this instance, the negative emissions it reported and used in its Kyoto Protocol accounting would be unjustified. 


\section{Fermentation processes}

Industrial processes where large amounts of relatively pure $\mathrm{CO}_{2}$ are generated are optimal for a CCS project. For example, $\mathrm{CO}_{2}$ from fossil sources is generated in large amounts in hydrogen and ammonia production. The most important industrial process producing large amounts of $\mathrm{CO}_{2}$ from biomass is fermentation.

Fermentation of sugars in ethanol production produces large amounts of relatively pure $\mathrm{CO}_{2}$. Capture of the $\mathrm{CO}_{2}$ from the process is technically easy and cost-efficient. Increased global demand of biofuels has increased ethanol production in recent years, and in this context BECCS projects could become more attractive.

In national GHG inventories $\mathrm{CO}_{2}$ emissions from the sugarcane fermentation process would not be reported, as the emissions result from short-rotation biomass.

Emissions and removals associated with sugarcane cultivation need to be reported in several places:

- the energy sector (emissions from fuel use in planting and harvesting machinery, transport);

- the industrial processes sector (emissions from the fertiliser manufacture);

- the agricultural sector (emissions from the application of fertiliser and burning of agricultural residues);

- the LULUCF sector (carbon stock changes in soils due crop cultivation, and also emissions related to land-use changes where applicable).

All relevant emissions should be covered in national inventories; however they would not be allocated to sugarcane cultivation. In some cases the emissions could also be reported in inventories of other countries, e.g. if the fertiliser used was imported. Reporting of some of the emissions, such carbon stock changes in soils, would also require country-specific methodologies and detailed activity and emission factor data.

The emissions from the capture and storage of the $\mathrm{CO}_{2}$ would be reported in a similar way as in the example on CHP in the pulp and paper industry above. The reporting of captured amount could be reported, for example, under Industrial Processes in category 2.D - Other Production.

The accounting of the reduced emissions under the Kyoto Protocol is again as set out in the pulp and paper industry example above. Sugarcane is a short rotation plant and the carbon stock changes (gains through growth of biomass and loss due to the harvest) are not part of inventory reporting, as the growth and losses of carbon compensate each other over a short period of time. The sustainability of the biomass could be assessed taking into account other factors, for example, what are the emissions from cultivation (carbon stock changes in soils, emissions from fertilisation and liming) and has it induced any land-use change.

As with the hypothetical example of CHP in the pulp and paper industry, instances may arise where all the emissions associated with a BECCS project using sugar cane are not accounted for.

If the capture and storage of $\mathrm{CO}_{2}$ from fermentation of sugarcane to ethanol were implemented as a CDM project, the accounting of the certified emission reduction units (CERs) resulting from the project would be estimated from emission reductions compared to a baseline. The methodology for estimating the baseline and project emissions would need to be accepted by the CDM Executive Board. The baseline could simply be based on estimates of emissions from the production of ethanol without the capture and storage. Where the boundaries are set could have a critical impact on how many CERs the project would result in.

The accuracy of the GHG reporting and accounting under such CDM projects is likely to rely to a great extent on the requirements placed on CCS (and therefore BECCS) projects as a condition of their acceptance by the CMP. 


\section{Conclusion}

With the principal attraction of BECCS, its ability to deliver negative carbon emissions, becoming better known, this paper reviews the treatment of negative emissions under current and planned carbon accounting arrangements. It finds that under current UNFCCC reporting guidance, as they apply to Annex I Parties, there is only cursory mention of CCS and no mention of BECCS, and in accounting guidance relating to the Kyoto Protocol there is no mention of either. However, it is notable that this has not prevented Annex I Parties from using CCS to help meet their Kyoto Protocol obligations. No CCS projects have been implemented under JI to date, and CCS is not currently recognised as valid for CDM projects.

The IPCC has developed new guidelines that are available for use by non-Annex I Parties. They have yet to be adopted for reporting by Annex I Parties under the UNFCCC, but this is anticipated with a 2015 start date. The revised guidelines set down methodological guidance for CCS that are strict and should provide greater certainty for those countries interested in adopting the technology. Encouragingly, they also appear to apply equally to BECCS and allow for the reporting of negative emissions.

However, as they currently stand the new guidelines do not tackle a critical issue that has implications for all biomass energy systems: the sustainability of the biomass. There are two potential BECCS scenarios where this could be a cause for concern.

The first relates to a BECCS project in an Annex I Party country where the biomass is imported from a non-Annex I Party (i.e. developing) country. Reporting requirements under the UNFCCC will continue to differ considerably between Annex I and non-Annex I Parties. Therefore, while it may be possible to assess the sustainability credentials of the biomass used in BECCS where it is sourced domestically or from another Annex I Party country, this is unlikely to be possible where it is sourced from a non-Annex I Party country.

The ability to conduct a proper assessment of the sustainability of biomass imported from a developing country would be heavily reliant on the quality of their GHG reporting. The country of source, being a non-Annex I Party, would not produce an annual inventory, and the quality of its national communication is unlikely to be sufficient to allow sustainability to be assessed. This could lead to a situation where an Annex I Party could report and account negative emissions from BECCS, even where the biomass used caused significant emissions in the country where it was produced.

A reasonable conclusion therefore is that such a BECCS project might be subject to scepticism about its sustainability unless additional biomass sourcing safeguards were provided.

There may even be uncertainty for BECCS projects in Annex I Party countries where the biomass is domestically sourced. While it may be possible to assess the sustainability credentials of the biomass from the annual national GHG inventory, where LULUCF sector reporting is required, this may not necessarily provide the complete picture depending on optional choices made by the Party in question. Complete LULUCF reporting is not compulsory and accounting for land use changes in accordance with the Kyoto Protocol may also be incomplete. Consequently, an Annex I Party operating a BECCS project that uses unsustainable domestically sourced biomass appears unlikely to suffer any penalty, depending on the choices it has made under the Kyoto Protocol.

Therefore, in final conclusion, while uncertainty surrounding the overall validity of BECCS may be receding with the imminent adoption of revised carbon reporting and accounting guidance, there remains a need to update biomass accountancy policy to ensure, to the best extent possible, mandatory and accurate emissions reporting. This should be prerequisite for supporting and incentivising BECCS as a carbon reduction technology (IEA, forthcoming). 


\section{References}

Fisher, B.S., et al. (2007), "Issues related to mitigation in the long term context", in B. Metz et al. (Eds.), Climate Change 2007: Mitigation of Climate Change. Contribution of Working Group III to the Fourth Assessment Report of the Intergovernmental Panel on Climate Change, Cambridge University Press, Cambridge, United Kingdom and New York, United States, pp. $169-250$.

Global CCS Institute (2010), Global Status of BECCS Projects, H. Karlsson and L. Byström, Biorecro $A B$, Stockholm, Sweden.

IEA (International Energy Agency) (2010), Energy Technology Perspectives 2010, OECD/IEA, Paris.

IEA (forthcoming), A Policy Strategy for Carbon Capture and Storage, OECD/IEA, Paris.

IPCC (Intergovernmental Panel on Climate Change) (2006), 2006 IPCC Guidelines for National Greenhouse Gas Inventories, S. Eggleston et al. (Eds.), IPCC and IGES, Hayama, Japan, www.ipcc-nggip.iges.or.jp/public/2006gl/index.htm.

IPCC (2011), Special Report on Renewable Energy Sources and Climate Change Mitigation, Working Group III Mitigation of Climate Change, Potsdam Institute for Climate Impact Research (PIK), Potsdam, Germany, http://srren.ipcc-wg3.de/report.

UNFCCC (United Nations Framework Convention on Climate Change) (2005), Guidelines for preparation of the information required under Article 7 of the Kyoto Protocol, (Ref:

FCCC/KP/CMP/2005/8/Add. 2. pp. 54-66). 


\section{Annex 1: Preparation of annual GHG inventories under the UNFCCC and Kyoto Protocol}

\section{Page 22 Annex I Parties}

Annex I Parties to the UNFCCC are required to prepare annual GHG inventories using the following methodologies, set out in reports by the IPCC:

- revised 1996 IPCC Guidelines for National Greenhouse Gas Inventories (1997);

- IPCC Good Practice Guidance and Uncertainty Management in National Greenhouse Gas Inventories (2000);

- $\quad$ IPCC Good Practice Guidance for Land Use, Land-Use Change and Forestry (2003).

Annex I national GHG inventories are reviewed annually by international expert review teams coordinated by the UNFCCC secretariat. The inventories need to be transparent, consistent, comparable, complete and accurate and be submitted on time. Failure to meet the reporting requirements specified in decisions under the Protocol results in that Party losing its eligibility to participate in the Kyoto Protocol mechanisms, namely emissions trading, $\mathrm{JI}$ and CDM projects.

The IPCC guidelines give methods for calculation of emissions and removals of specific greenhouse gases using different tiers. The methods range from simple multiplications of activity data with emissions factors, to complex equations taking into account the dependence of emissions from several parameters. The IPCC default, or Tier 1, methods are usually based on country-specific activity data and use of IPCC default emission factors or parameters. These methods should be only used for very small sources. In Tier 2, country-specific emission factors/parameters reflecting the national circumstances are used to provide more accurate estimates. Tier 3 methods are often sophisticated, and complex, and based on, for example, use of plant-specific data and measurements or detailed models. Models are particularly used in the agriculture and LULUCF sectors for categories where several factors affect emissions.

It should be noted that national methodologies can be used to prepare annual GHG inventories in cases where they better reflect the national circumstances. However, they must still be consistent with the IPCC guidelines and good practice guidance, and be well documented and scientifically based.

\section{Non-Annex I Parties}

The methodological guidance for non-Annex I Parties is the same as for Annex I Parties, but nonAnnex I Parties have more flexibility in the choice of methods as the use of the IPCC guidelines and good practice guidance is not mandatory. Non-Annex I Parties are also encouraged to use the 2006 IPCC Guidelines for National Greenhouse Gas Inventories (2006).

GHG inventories are provided in the national communications by these countries, currently approximately at four-year intervals. Guidelines for the preparation of national communications include guidance on methodologies and reporting for GHG inventories.

Non-Annex I Parties do not need to provide full time series for national emissions and removals. Reporting has been required only for specific years: in the initial national communication for the year 1994, and in the second national communication for the year 2000. 
In addition, descriptions of methodologies, data collection and choice of emission factors is only required at a very general level. The quality, completeness and transparency of the GHG inventories of non-Annex I Parties have varied significantly.

\section{Annex 1 References}

IPCC (Intergovernmental Panel on Climate Change) (1997), Revised 1996 IPCC Guidelines for National Greenhouse Gas Inventories Vols. 1-3, J. T. Houghton et al. (Eds.), IPCC, OECD and IEA, London, United Kingdom, www.ipcc-nggip.iges.or.jp/public/gl/invs1.htm.

IPCC (2000), Good Practice Guidance and Uncertainty Management in National Greenhouse Gas Inventories, J. Penman et al. (Eds.), IPCC, IGES and IEA, Hayama, Japan, www.ipccnggip.iges.or.jp/public/gp/english/.

IPCC (2003), Good Practice Guidance for Land Use, Land-Use Change and Forestry, J. Penman et al. (Eds.), IPCC and IGES, Hayama, Japan, www.ipccnggip.iges.or.jp/public/gpglulucf/gpglulucf.htm.

IPCC (2006), 2006 IPCC Guidelines for National Greenhouse Gas Inventories, S. Eggleston et al. (Eds.), IPCC and IGES, Hayama, Japan, www.ipcc-nggip.iges.or.jp/public/2006gl/index.htm. 


\section{Annex 2: Hypothetical example of reporting national emissions and removals under the UNFCCC and Kyoto Protocol}

Table 1 presents the reporting and accounting for a hypothetical Party that has elected to account for all activities under Article 3.4 of the Kyoto Protocol.

Table 1 Hypothetical example of reporting national emissions and removals

\begin{tabular}{|c|c|c|c|}
\hline & $\begin{array}{c}\text { Reporting } \\
\mathrm{Tg} \mathrm{CO}_{2} \text { eq (1) }\end{array}$ & $\begin{array}{l}\text { Accounting } \\
\mathrm{Tg} \mathrm{CO}_{2} \text { eq }\end{array}$ & $\begin{array}{l}\text { Assessment of compliance } \\
\qquad \mathrm{Tg} \mathrm{CO}_{2} \text { eq (2) }\end{array}$ \\
\hline & \multicolumn{2}{|c|}{$\begin{array}{l}\text { Annual or average annual } \\
\text { emission/removals }\end{array}$} & \\
\hline \multicolumn{4}{|l|}{ Base year } \\
\hline Total emissions without LULUCF & 100 & - & - \\
\hline Assigned amount (QELRO = -8\%) (3) & 92 & 92 & $460(3)$ \\
\hline LULUCF sector & -28 & - & - \\
\hline FM, ARD & Not reported & - & - \\
\hline CM & 3 & 3 & $15(4)$ \\
\hline GM & -2 & -2 & $-10(4)$ \\
\hline RV & -0.2 & -0.2 & $-1(4)$ \\
\hline $\begin{array}{l}\text { Total assigned amount with additions/ } \\
\text { subtractions from Article } 3.3 \text { and } 3.4\end{array}$ & & & 486 \\
\hline \multicolumn{4}{|l|}{ Commitment period (2008-2012) } \\
\hline Total emissions without LULUCF & 98 & 98 & 490 \\
\hline LULUCF sector & $-30(5)$ & - & - \\
\hline ARD & $3(6)$ & $0(7)$ & $0(7)$ \\
\hline FM (cap $\left.3 \mathrm{Tg} \mathrm{CO}_{2} \mathrm{Eq} / \mathrm{yr}\right)(8)$ & -32 & -3 & -15 \\
\hline CM & 4 & 4 & $20(4)$ \\
\hline GM & -3 & -3 & $-15(4)$ \\
\hline RV & -0.5 & -0.5 & $-2.5(4)$ \\
\hline Total emissions to be accounted for & & & 477.5 \\
\hline
\end{tabular}

(1) Emissions are presented as positive and removals as negative values in the table.

(2) Assessment of compliance for the first commitment period of the Kyoto Protocol is based on emissions during the commitment period (five-year period) and five times base year emissions, where applicable.

(3) The assigned amount is equal to five times the total emissions in the base year without the LULUCF sector times five and times the quantified emission limitation/reduction obligation (QELRO) of the Party given in Annex B of the Kyoto Protocol. The Party will be in compliance with its emissions reduction/limitation commitment if its emissions during the commitment period are equal or below the assigned amount. In addition, additions and subtractions of units acquired from emissions trading, $\mathrm{Jl}$ and CDM projects as well as from LULUCF activities under Article 3 are taken into account in accordance with accounting rules defined in the Kyoto Protocol and subsequent decisions under the Protocol.

(4) The base year emissions/removals of CM, GM and RV times five will be compared with the corresponding emissions in the commitment period and the difference will be added/ subtracted from the assigned amount for assessment of compliance.

(5) The net emissions/removals of LULUCF activities under the Kyoto Protocol (ARD, FM, CM, GM and RV) can differ from the total net emissions/removals of the LULUCF sector as the LULUCF activities under the Kyoto Protocol may not cover all managed land in the country. For example, some managed forest land could be excluded from the forest management activity, and some net emissions/removals be excluded from the accounting (in this case $-2.5 \mathrm{Tg} \mathrm{CO}_{2} \mathrm{eq} / \mathrm{yr}$ ).

(6) Net average annual emissions during the commitment period on areas afforested, reforested and deforested since 1990.

(7) The net removals from $\mathrm{FM}$ can be used to compensate net emissions from ARD up to $9 \mathrm{Mt} \mathrm{C} /$ year ( $33 \mathrm{Tg} \mathrm{CO} /$ per year).

(8) The cap is applied after the compensation of net emissions from ARD. 
In Table 1, the net accountable emissions are lower than the assigned amount including additions from Article 3, paragraphs 3 and 4. This means that the hypothetical Party would meet its commitments. If the net accountable emissions were higher, the Party would have to acquire credits from emissions trading, $\mathrm{JI}$ or CDM projects to cover the difference in order to meet its commitments. 


\section{Annex 3: Example of reporting BECCS in annual national GHG inventory}

Table 2 provides an example of how avoided emissions from the application of BECCS would be Page 26 reported in an annual national GHG inventory. This uses biomass as a CHP fuel in the pulp and paper industry.

Table 2 Reporting of $\mathrm{CO}_{2}$ emissions and removals in the GHG inventory of a CHP plant in the pulp and paper industry

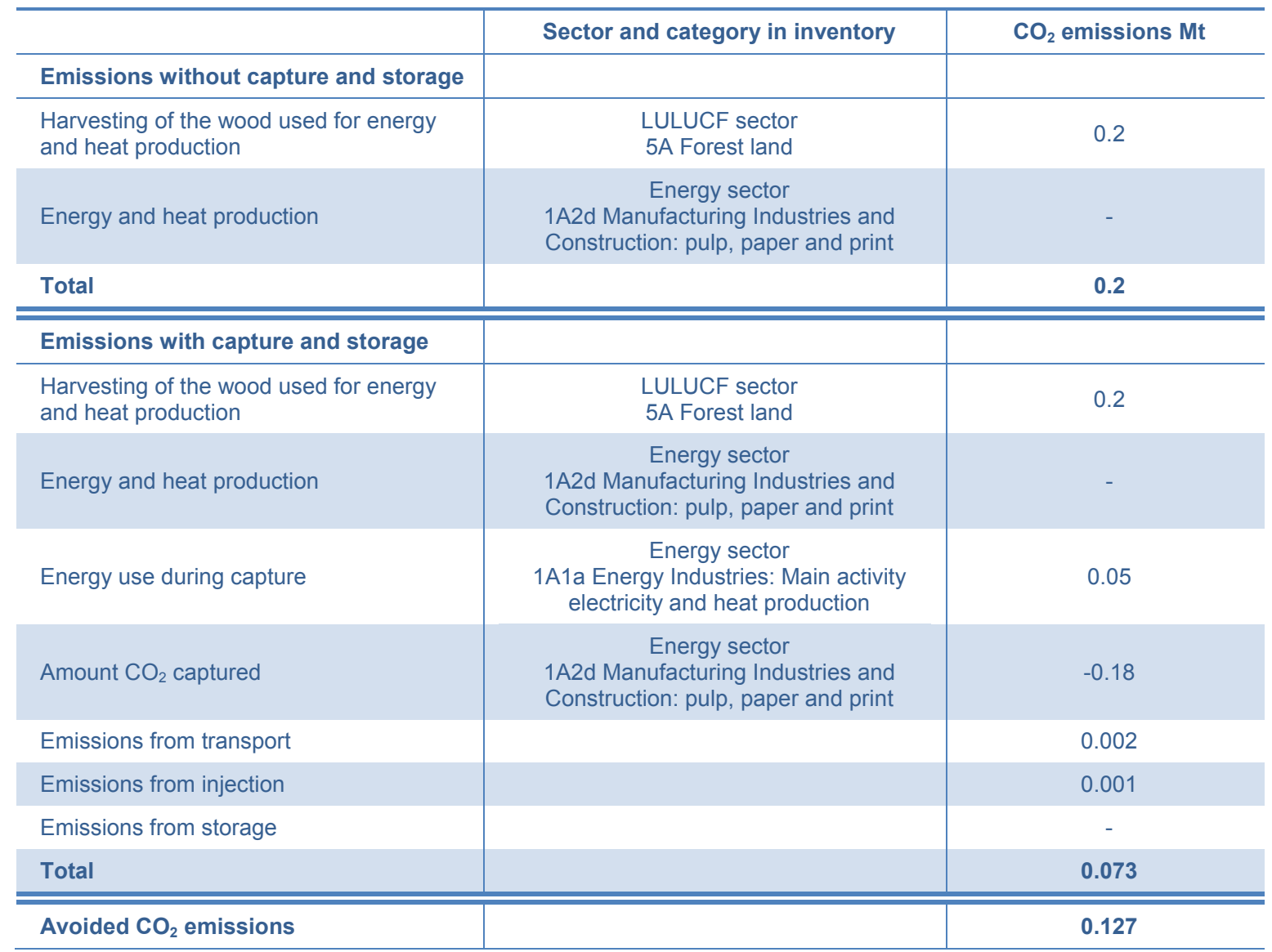




\section{Acronyms, abbreviations and units of measure}

\section{Acronyms and abbreviations}

$\begin{array}{ll}\text { ARD } & \text { afforestation/reforestation and deforestation } \\ \text { BECCS } & \text { bioenergy with CCS } \\ \text { CCS } & \text { carbon capture and storage } \\ \text { CDM } & \text { Clean Development Mechanism } \\ \text { CER } & \text { Certified Emission Reduction unit } \\ \text { CM } & \text { cropland management } \\ \text { CMP } & \text { meeting of the parties to the Kyoto Protocol } \\ \text { CO }_{2} & \text { carbon dioxide } \\ \text { CRF } & \text { Common Reporting Framework } \\ \text { FM } & \text { forest management } \\ \text { GHG } & \text { greenhouse gas } \\ \text { GM } & \text { grazing land management } \\ \text { IEA } & \text { International Energy Agency } \\ \text { IPCC } & \text { Intergovernmental Panel on Climate Change } \\ \text { JI } & \text { Joint Implementation } \\ \text { LULUCF } & \text { land use, land-use change and farming } \\ \text { RV } & \text { revegetation } \\ \text { UNFCCC } & \text { United Nations Framework Convention on Climate Change }\end{array}$

\section{Units of measure}

$\begin{array}{ll}\mathrm{CO}_{2} \text { eq } & \mathrm{CO}_{2} \text { equivalent } \\ \mathrm{km} & \text { kilometre } \\ \mathrm{MW} & \text { megawatt } \\ \mathrm{Mt} & \text { million tonnes } \\ \mathrm{ppm} & \text { parts per million } \\ \mathrm{Tg} & \text { teragram } \\ \mathrm{t} & \text { tonne }\end{array}$




\section{Glossary}

Annex I Party

Bioenergy with CCS (BECCS)

Carbon Capture and Storage (CCS)

Clean Development Mechanism (CDM)

Certified Emission Reduction Unit (CER)

Common Reporting Framework (CRF)

Joint Implementation (JI)

Kyoto Protocol

National Greenhouse Gas Inventories

Non-Annex I Party

Tier 3 Level Reporting

United Nations Framework Convention on Climate Change (UNFCCC)
A party to the UNFCCC which is an industrialised country or a country with an economy in transition.

A combination of biomass processing or combustion with CCS; it involves applying CCS technology to biomass $\mathrm{CO}_{2}$ point emission sources.

A process consisting of the separation of $\mathrm{CO}_{2}$ from energy-related, industrial or other sources, transport to a storage location and injection into geological formations for the purposes of long-term isolation from the atmosphere.

A system by which Annex I Parties can meet their reduction or limitation commitments by investing in GHG emission reduction or removal projects in non-Annex I Party countries.

A type of carbon credit issued by the CDM Executive Board for emission reductions achieved by CDM projects; can be used by Annex I Parties to comply with emission limitation commitments.

An inventory submission for Annex I Parties comprising a series of standardised data tables containing mainly numerical information, submitted electronically.

A mechanism by which Annex I Parties can meet their reduction or limitation commitments by investing in GHG emission reduction or removal projects in another Annex I Party country.

A protocol to the UNFCCC that sets binding targets for 37 industrialised countries and the European Union to reduce GHG emissions.

A report detailing annual emissions and removals of greenhouse gases, to be submitted annually by Annex I Parties.

A party to the UNFCCC which is a developing country.

The most detailed level of reporting required under the 2006 IPCC climate reporting Guidelines, using plant-level methodology. The Guidelines stipulate Tier 3 reporting for CCS, as geological formations used to store $\mathrm{CO}_{2}$ under CCS technologies are highly heterogeneous.

An international environmental treaty with the objective to stabilise greenhouse gas concentrations in the atmosphere at a level that would prevent dangerous anthropogenic interference with the climate system. 


\section{iea}

\section{International Energy Agency}
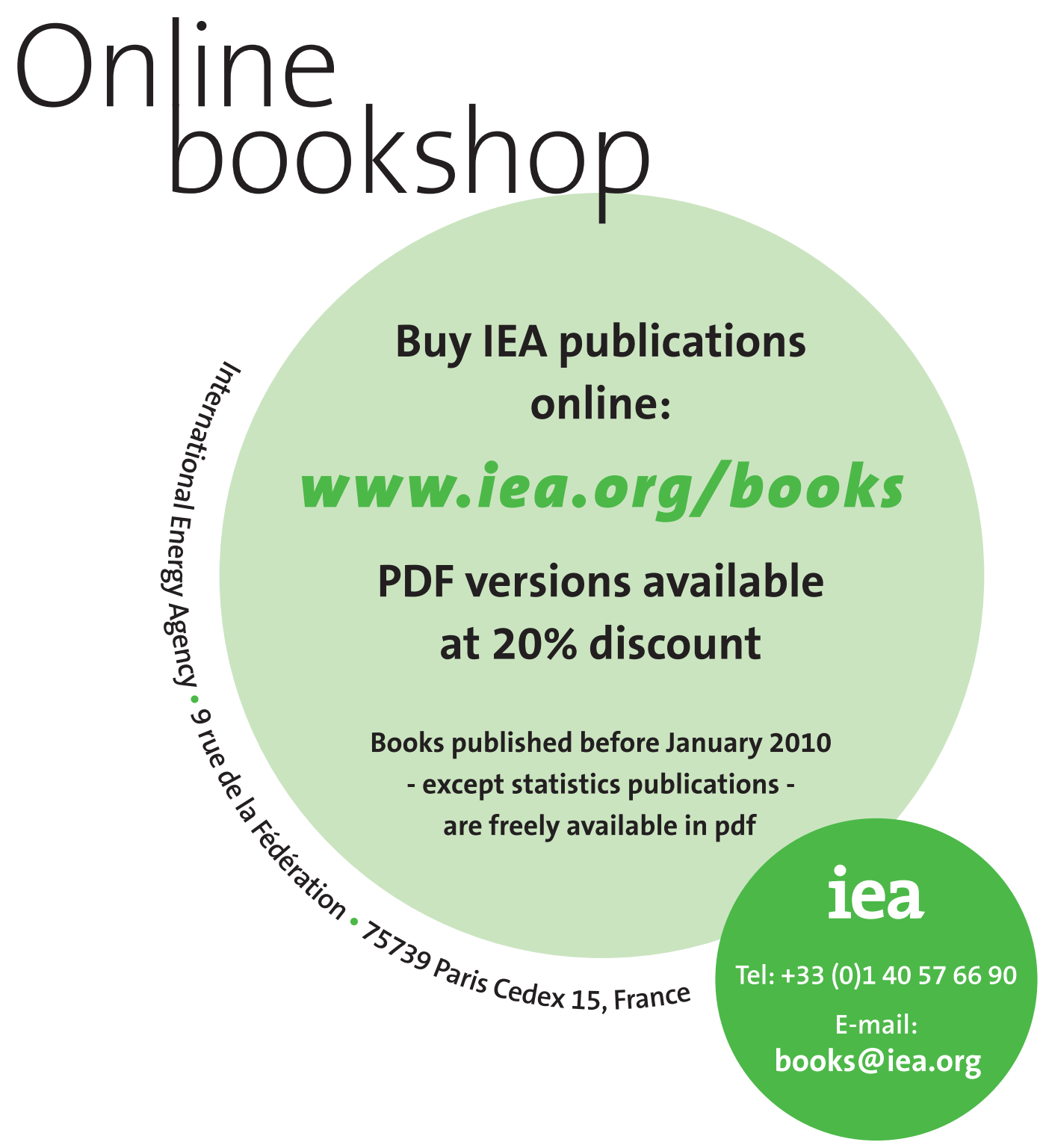


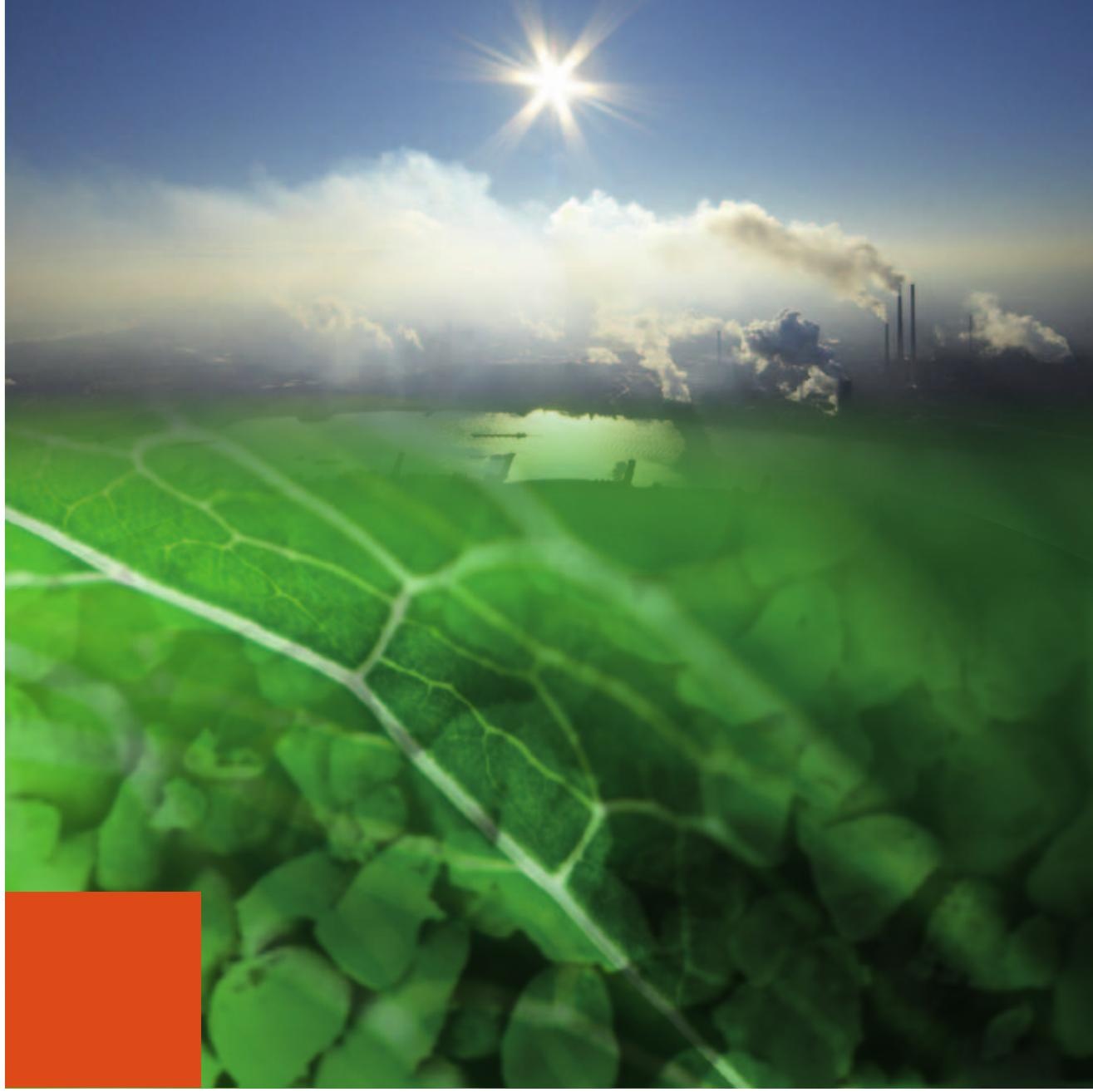

International Energy Agency

9 RUE dE LA FÉdÉRATION 75739 Paris Cedex 15

www.iea.org 